\title{
A reappraisal of the ocular lesion known as Bitot's spot
}

\author{
By F. C. RODGER,* H. SAIDUZZAFAR, A. D. GROVER AND A. FAZAL \\ Institute of Ophthalmology, Aligarh University, India
}

(Received 5 December 1962-Revised I 8 July 1963)

The lesion under discussion is universally known as Bitot's spot, somewhat unjustifiably in view of a predated description by Hubbenet (1860). Hubbenet was Chief Medical Officer of the small French Army in the Crimea: his observations on nutritional xerosis were carried out on soldiers and prisoners in that campaign. $\mathrm{He}$ stated that he had found certain superficial changes in the eye, in most instances associated with night-blindness; these changes in his view resulted from fatty degeneration. The main feature, said Hubbenet, was a dry patch of epithelial degeneration on the exposed area of the bulb from which small waxy scales sloughed off. Hubbenet also observed that in severe cases the cornea lost its lustre. It seems probable that as an oculist in Bordeaux Bitot had access to the journal in which an abstract of Hubbenet's lecture appeared, but he makes no mention of him. Bitot's (1863) paper tells us much more than the abstract of Hubbenet's lecture, which perhaps explains why his name has persisted and Hubbenet's is now forgotten. Bitot described numerous small white spots or short lines, aggregated to form pearly or silvery discs on the exposed areas of the eyeballs, and claimed that they were always associated with night-blindness; in fact he coined the term tâche héméralopique. Like Hubbenet, he categorized the lesion as an epithelial metaplasia. He stressed that the twenty-nine children comprising his series were neither scrofulous, adenoidal nor rachitic; this suggests that they were healthy-looking children. Although diffuse xerosis of the eye was an established clinical entity, nobody seems at that time to have related the two conditions. Almost 20 years later this still held true. Snell (1880-I) called the spots vaguely 'a peculiar appearance associated with night blindness'. Although Saemisch $(1876)$ used the term epithelial xerosis to describe the diffuse lesion, now known as xerophthalmia, we cannot find any evidence that the spots described by the two French workers were classified by anyone as a type of xerosis until the turn of the century when this was the term used by Herbert ( 1897$)$ and Stephenson (1898); thereafter this opinion was increasingly held. It was, however, as a result of the experimental work of McCollum \& Simmonds (I9I7) and Osborne \& Mendel (1921) and especially Goldblatt \& Benischek (1927), the latter being the first to induce a generalized xerophthalmia in experimental animals by means of a diet deficient in vitamin A only, that the localized lesion (called Bitot's spot now) rightly or wrongly came to be considered as a modified manifestation of xerophthalmia peculiar to man (Treacher Collins, 1930).

Many slightly different descriptions of the spots have been given. What is missing

- Present address: Princess Margaret Hospital, Okus Road, Swindon, Wilts. 
is a logical explanation for the differences and a satisfactory connexion between the clinical appearances and vitamin A deficiency, for no one to date has been able to reproduce the lesion experimentally. There have been arguments about the origin and nature of the foam which covers the epithelium, whether or not the spots are associated with raised rod thresholds, and whether they are evidence of vitamin A deficiency in the present or the past, and if the deficiency causing them is acute or chronic, mild or severe. Conflicting views have also been held on their association with reduced blood levels of the vitamin, and their response to vitamin A administration. In fact, full agreement has not been reached on any of the important points. It is, however, generally held that Bitot's spots are a manifestation of avitaminosis $\mathrm{A}$. The purpose of this study is to appraise such a claim.

\section{EXPERIMENTAL}

\section{Subjects}

Muslim and Hindu peasants resident in the Uttar Pradesh of India of both sexes and all ages were examined with the usual optical instruments; in addition five other special types of examination were carried out.

\section{Special examinations}

Physical status. The 'body type' was classified for children in accordance with the classic description of Bloch ( $192 \mathrm{I} a, b)$. Type I describes the pot-bellied child who is emaciated, weak and lethargic. Type 2 describes the child who is weakly but at first sight well nourished; he is in fact oedematous, and not well nourished. Type 3 is the child who is stunted, weak and generally rather emaciated without a marked potbelly. Whether or not a subject was debilitated was determined roughly by measuring his height and weight, and by noting the body-fat thickness. A final assessment was then made by comparison with the control group, taking into account age, sex and religion (on which the dietaries largely depend).

Light thresholds. The Goldmann-Weekers dark adaptometer is suitable for testing night vision, although the method is time-consuming ( $\mathrm{h}$ for each patient). Subjective accuracy is difficult to assess, but with the type of patient we dealt with we reckoned it to be within 0.1 log unit. The lamp illuminating the test object can be calibrated at the beginning by means of a test bulb and a built-in photometer; the latter also measures the sphere luminance used in the initial light adaptation; thus uniformity between different subjects is obtained. A built-in stabilizer ensures further uniformity of brightness for current fluctuations of $\pm 10 \mathrm{~V}$. The highest luminance of the test object selected was 3.42 apostilbs $(3.1$ apostilbs $=0.3$ I millilambert).

The eyes of our patients were first light-adapted, a sphere luminance of $3000 \mathrm{~lx}$ being used; subsequently we plotted the development of dark adaptation using as test object a large striped field giving $100 \%$ contrast. The eye was $30 \mathrm{~cm}$ from the testplate, which consisted of two parallel black stripes I cm apart, the whole being $56 \mathrm{~mm}$ in diameter. Each patient indicated when he could see the stripes on the light intensity 
being gradually increased from complete darkness to the 'just-seen' level. Meanwhile, a drum automatically revolved at a set speed, the different points on the curve being imprinted on the logarithmic graph paper by a lever depressed by the experimenter when the subject replied affirmatively. The threshold was shown in log units as the ordinate, and the time in min as the abscissa. The curves when plotted were compared with one of four sets of standard curves supplied with the apparatus for different age groups.

Plasma levels of vitamin A and carotenoids. A Bausch and Lomb colorimeter and a similar apparatus devised and built in the Dunn Nutritional Laboratory, University of Cambridge and Medical Research Council, were used for the blood assays. We found the arm of the Pye galvanometer incorporated in the Cambridge instrument more stable and preferred it to the other; by using both from time to time a useful check on the accuracy of the results was possible. The technique used to determine the vitamin A and carotenoids in the blood samples was that described by Moore (1957). The accuracy of our technique was further checked by Dr I. M. Sharman of the Dunn Nutritional Laboratory, who kindly assayed several serums previously assayed by us in India. The levels found in the two laboratories were very close.

Biopsies. Several conjunctival specimens were examined microscopically, not only those in which Bitot's spots were present, but also from healthy eyes. The conjunctiva in the upper fornix was also examined, as was the debris covering the spots. In addition to the usual routine techniques, we used DOPA, PAS and Weigert's elastic tissue stain. The debris and conjunctival secretions were cultured in several instances:

Response to therapy. The effect of treatment on the external ocular membranes, the visual acuity and the dark adaptation tests played an important part in the final assessment of the lesions. After an initial intramuscular injection of 300000 i.u. of vitamin A (Arovit, Hoffman-La Roche Ltd, Basle), 100000 i.u. daily were given orally for several months, because of the lack of response. No other supplement was added to the diet, and as the patients continued to be fed as before by their relatives a true determination of the effect of vitamin A therapy was possible.

\section{RESULTS}

\section{Blood levels}

The majority of the blood levels of vitamin $A$ and carotenoids in a random sample of 108 patients of both sexes with healthy eyes and normal light thresholds was found to lie between 58 and 108 i.u. and 20 and $55 \mu \mathrm{g}$ per $100 \mathrm{ml}$ plasma respectively (Fig. I); overall the range lay between zero and 260 i.u. vitamin $A$ and zero and $\mathrm{I} 10 \mu \mathrm{g}$ carotenoids per $100 \mathrm{ml}$. The means were 126.4 i.u. vitamin A and $44^{.1} \mu \mathrm{g}$ carotenoids, with standard deviations of $\pm 93^{\circ} 0$ and $\pm 10^{\circ} 5$ respectively. They agree closely with the mean levels found by Burch, Salcedo, Carrasco \& Intengan (1952) in the Philippines, where the means were $\mathrm{r} 39$ i.u. and $47 \mu \mathrm{g}$ respectively. In twenty-five healthy Indonesian children (the state of the ocular membranes not being recorded) Yap-KieTiong (1957) found almost identical vitamin A levels but higher carotenoid levels: I 49 i.u. and $82 \mu \mathrm{g}$ respectively. The levels we found agreed with those found by 
another team of workers in our Institute, who were studying the possible effect of intestinal parasites on the vitamin A status (Rodger, Dhir \& Hosain, 1960).

In the subjects investigated in this preliminary study, the range of levels in those without any ocular abnormality was so wide that the individual assays were of little value. Therefore, we laid emphasis upon the mean of the levels found in any one group of subjects and upon any tendency for the range of levels to be more frequently low. The variable relationship between the vitamin $A$ and the carotenoid levels was noteworthy. When the vitamin A value was low or nil, the carotenoid value frequently stayed around $25 \mu \mathrm{g} / 100 \mathrm{ml}$. We conclude that this latter figure probably represents

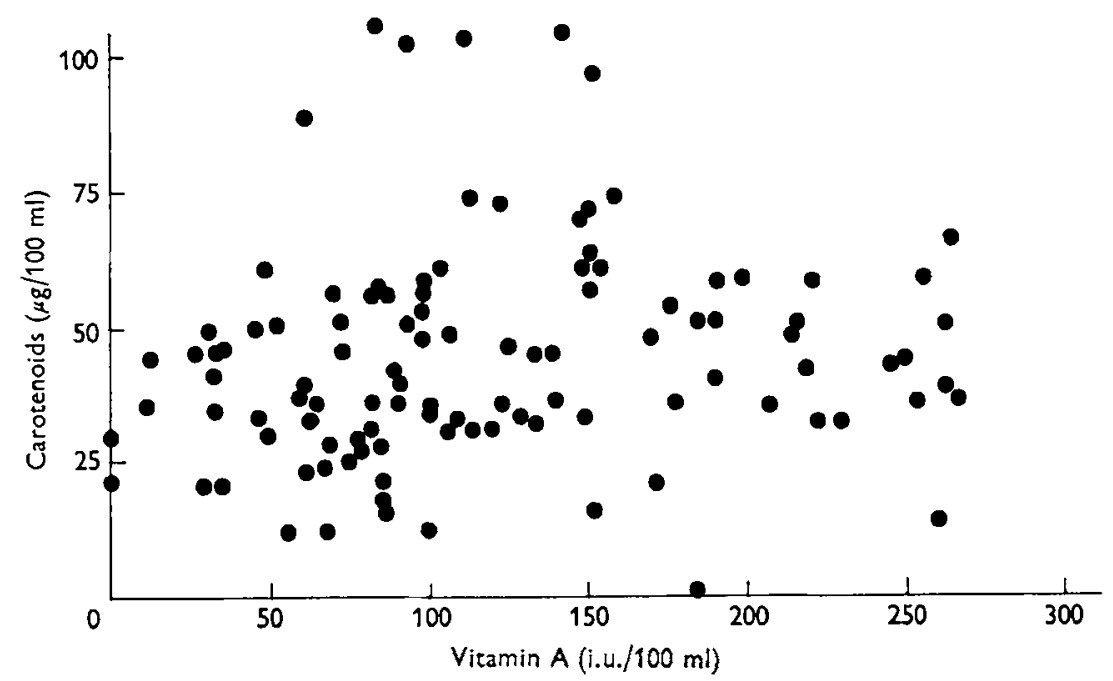

Fig. I. Distribution of the vitamin $A$ and carotenoid blood levels in a random sample of 108 Indians of mixed race, all with healthy eyes.

that proportion of the carotenoid pigments not capable of acting as provitamin $\mathrm{A}$ (such as xanthophylls). Another possible explanation is that the amount of these pigments in the diet was greater than that of the pigmented provitamins so that, although the latter may be absent at certain seasons of the year, the former, the xanthophylls, are still present in the plasma. Again, there may be more liberal reserves of the non-provitamins in the body fat or elsewhere, or the reserves may be more slowly liberated, utilized, excreted or destroyed.

\section{Appearance of Bitot's spots}

Bitot's spots were usually bilateral $(95 \%)$ and nearly always occurred on the temporal side of the cornea on the exposed part of the bulb ( $98 \%)$. They were round, oval, triangular or polyhedral, and always large enough to be seen with the naked eye; neither the appearance nor the incidence in children differed from those in adults. The debris was the most striking feature of the lesion and suggests a convenient descriptive clinical classification. There were two principal types, in one of which the debris was pearly in appearance and in the other mucoid. Rarely, mucoid material was scattered across the bulb and there was no spot; sometimes both features were present. The 
blood vitamin A and carotenoid levels associated with these two types did not differ: the range was wide (Fig. 2), the levels being similar to those found in healthy subjects without Bitot's spots (Fig. I). In sixty-two patients with Bitot's spots the mean levels were $r 20 \mathrm{i} . \mathrm{u}$. and $42 \mu \mathrm{g}$ respectively; the patients exhibited none of the physical changes described by Bloch $(1921 a, b)$. In six of these subjects the blood levels were lowmeans of 17.5 i.u. and $26.9 \mu \mathrm{g}$. In only three of them were the spots associated with raised light thresholds. This proportion is not unusually high, for in the area where we worked there are many causes of night-blindness in addition to a primary or secondary vitamin A deficiency (Rodger et al. 1960).

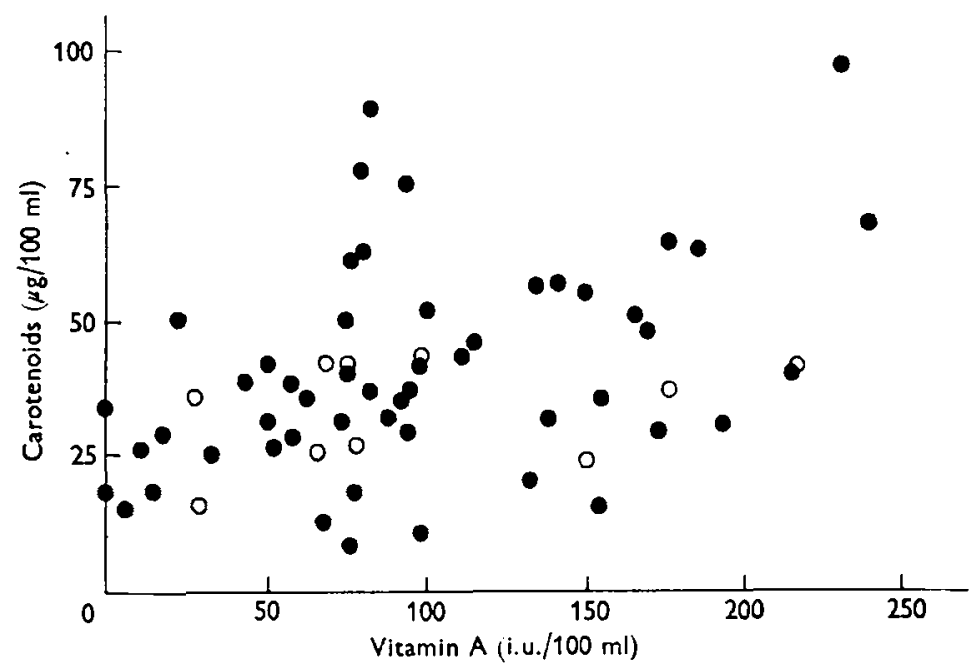

Fig. 2. Distribution of the vitamin $A$ and carotenoid blood levels in fifty-two subjects exhibiting pearly spots $(\bullet)$ and in ten exhibiting mucoid spots $(O)$.

The pearly spot (Pl. I). This lesion was seen in fifty-two healthy well-nourished people; the dark adaptation was normal (except in three). The eyes were lustrous and not congested. The blood vitamin A and carotenoid levels were reasonable except in four subjects. The means were normal. Usually there was nothing in the history or physical appearance to indicate that the subject was suffering or had suffered from avitaminosis $\mathrm{A}$. The fact that four subjects only had low blood values, three having raised light thresholds and the fourth a small iris prolapse, does not materially affect our conclusion that the pearly spot is not a manifestation of vitamin A deficiency.

The conjunctival epithelium in the region of the pearly spot was covered with a white waxy pearl-like debris, slightly raised above the surface, and not easily scraped off. The surrounding area was congested for a millimetre or so. Closer examination with the biomicroscope revealed that the pearl-like appearance arose from the presence of a number of air bubbles embedded in a waxy material, rather like milk before it comes to the boil. It has been said that these bubbles result from a vesicular formation of the underlying epithelium, which, however, we were unable to confirm microscopically. The bubbles were true bubbles filled with air, presumably resulting from the constant mixing of the debris, or of tears with the debris, by the eyelid movements. 
In general the Meibomian glands and lid margins were healthy in these subjects. On the other hand, an unusually large number of xerosis bacilli (Corynebacterium xerosis) was present in the debris of the pearly spot, as well as some Morax-Axenfeld bacilli and staphylococci. These bacteria lay in strands of distorted keratin, sloughed epithelial cells and occasional slips of mucus in the rugae of the unhealthy epithelium comprising the spot. Whatever the cause of the epithelial changes, the circumstances must be ideal for bacteria to colonize. The claim of Stephenson $(\mathrm{i} 898)$ that the pearly debris consists of colonies of Corynebacterium xerosis multiplying in the unhealthy epithelium seems probably correct; in this respect the organisms would be acting like the smegma bacillus.

The microscopic appearance of the epithelium was distinctive. It varied from a simple hyperplasia to a fully developed stratified squamous metaplasia with total loss locally of the mucus-secreting cells, which, however, are scanty even in health in this area. The mucus-secreting cells in the upper fornix (a region rich in such cells) were normal in appearance and number in our subjects and the flow of tears was unaffected. All other parts of the external eye were lustrous. Melanin pigment granules were found in all layers of the affected epithelial patch, more especially in the basal cells where they filled the cell bodies. In the prickle cells, and above, the granules formed a cap on the outer side of the nuclei. The DOPA technique, used in our investigations, showed that many of the basal cells exhibited a weak positive reaction, whereas in healthy eyes they did not. Pigment granules were also observed in the epithelium beyond the area affected, although in diminishing numbers. The capillaries in and around the spot were congested, forming the characteristic blue-red border around the spot. Vitamin A therapy even after many months had no effect upon the appearance of the pearly spot; such was also the experience of our colleagues at the Gandhi Eye Hospital when they treated similar cases with cod-liver oil or pure vitamin A. Berliner (1949) quotes several workers, including himself, who had the same lack of success.

The mucoid spot (Pl. 2). We examined ten such cases. The lesion was present in healthy people with normal light thresholds. Blood vitamin A and carotenoid levels were reasonably high except in two subjects. The means were normal. Vitamin A therapy did not cure the condition.

Only a few authors have mentioned that a mucus-like debris sometimes covers the spot (Herbert, 1897 ; Tobgy, 1935). The material covering this variety of spot differed considerably in consistency and appearance from that described as 'pearly'. The debris was more copious in the mucoid spot; it was sticky (like mucus), fragments sometimes being scattered indiscriminately over the external eye. Its colour resembled that of skim milk, grey-white rather than silver-white, and its surface was smooth and uniform unlike that of the pearly debris, which was papilliform. Inclusion bubbles were usually absent. Its abundance led to elevation of the surface. This type of debris was easily wiped off and reformed much more quickly than the other type, i.e. in a few hours. The mucoid material had the consistency and some of the usual staining reactions of mucus. When the debris was wiped away the conjunctiva might look healthy, or it might be raised, gelatinous and wet, or thickened, wrinkled and dry. On microscopic examination these phases coincided exactly with those of the pearly 
spot: a hyperplasia or metaplasia of the epithelium combined with loss of the mucussecreting cells locally. When there was little keratinization, the surface of the epithelial plaque was wet; when keratinization was advanced it was dry. Though these seem to be simply progressions of the same lesion, the nature of the mucoid debris in each stage was identical and at no stage could the lesion be linked with avitaminosis $A$. The whole bulbar conjunctiva was invariably hyperaemic, sometimes severely so. The pathologies of the two types of spot were identical, even to the distribution of pigment granules; the localized capillary congestion, however, a feature in the pearly spot, was lost sight of in the generalized hyperaemia which involved the external eye in the mucoid type. In the latter, some degenerate epithelial cells and leucocytes as well as a few xerosis bacilli and large colonies of diphtheroids, some Koch-Week's bacilli and an occasional pneumococcus were present. While the mucus-secreting cells locally were absent, those in the upper fornix had proliferated; at least there were many more per microscope field than in sections cut from identical areas in pearly spot cases and in twenty-three control biopsies.

Table I. Details of nine complicated cases of Bitot's spots out of sixty-two, the rest not being associated with any other lesion or defect

\begin{tabular}{|c|c|c|c|c|c|c|c|}
\hline \multirow[b]{2}{*}{ No. } & \multirow[b]{2}{*}{ Sex } & \multirow[b]{2}{*}{ Age } & \multicolumn{2}{|c|}{ Plasma } & \multicolumn{2}{|c|}{$\begin{array}{l}\text { Light threshold (log } \\
\text { units, Goldmann-Weekers } \\
\text { scale) }\end{array}$} & \multirow[b]{2}{*}{$\begin{array}{l}\text { Other lesions } \\
\text { or defects }\end{array}$} \\
\hline & & & $\begin{array}{l}\text { Vitamin A } \\
\text { (i.u./roo ml) }\end{array}$ & $\begin{array}{r}\text { Carotenoids } \\
(\mu \mathrm{g} / 100 \mathrm{ml})\end{array}$ & $\begin{array}{l}\text { Before } \\
\text { therapy }\end{array}$ & $\begin{array}{l}\text { After } \\
\text { therapy }\end{array}$ & \\
\hline$I$ & 우 & 32 & 0.0 & $29 \cdot 0$ & 0.125 & 0.000025 & Night-blindness \\
\hline 2 & 0 & 13 & 4.5 & $31 \cdot 0$ & 0.025 & 0.0000317 & Night-blindness \\
\hline 3 & $\sigma^{*}$ & 10 & 33.4 & $20 \cdot 0$ & 0.00125 & 0.000025 & Night-blindness \\
\hline 4 & 우 & 40 & $102 \cdot 8$ & $42 \cdot 0$ & 0.000035 & 0.000035 & $\begin{array}{l}\text { Pearly spot astride } \\
\text { limbus }\end{array}$ \\
\hline 5 & $\delta$ & 70 & $76 \cdot 0$ & 40.0 & 0.0005 & - & Xerosis of cornea \\
\hline 6 & $q$ & 20 & $28 \cdot 9$ & $35 \cdot 9$ & 0.00225 & 0.000020 & Myocephalon \\
\hline 7 & $\dot{q}$ & 16 & $217 \cdot 0$ & 40.0 & 0.000015 & 0.000015 & $\begin{array}{l}\text { Mucoid spot astride } \\
\text { limbus }\end{array}$ \\
\hline 8 & 우 & 50 & 69.8 & $4 I \cdot 5$ & 0.00003 & 0.000025 & As in 4 \\
\hline 9 & o & 18 & $x 17 \cdot 2$ & 37.0 & 0.000035 & 0.000035 & As in 7 \\
\hline
\end{tabular}

In our series the pearly variety was five times more common than the mucoid, but both are common in clinical ophthalmic practice in north India.

Of the sixty-two subjects exhibiting Bitot's spots examined in the course of this study, in fifty-three there was nothing to suggest an association with avitaminosis $\mathrm{A}$; in the nine cases detailed in Table I there were raised light thresholds (hemeralopia) in three, intrusions of the spot on to the cornea in four, xerosis of the cornea in one and myocephalon (single iris prolapse) in another. Of the nine, four only had low blood levels, the myocephalon case and the three cases of hemeralopia; only these four were true examples of avitaminosis $\mathrm{A}$. 


\section{DISCUSSION}

The probability that Bitot's spots reflect a nutritional disorder is supported by the many instances in which the lesion has been found in subjects on an inadequate diet. Even although Snell (I880-1) described his young patients as 'well fed children of the better-class artisan type', the fact that the condition was cured by administering cod-liver oil and iron suggests their diets were inadequate. Herbert (1897), working in India, was certain that the origin was improper and insufficient food. The frequency of this lesion in the tropics, he argued, was more likely to be due to chronic inanition than anything else. Yet, although Herbert said cod-liver oil and an improved diet cured some of his patients, it did not cure all. This observation of his has been constantly ignored despite many other papers confirming the lack of success of replacement therapy. Stephenson (1898) claimed that iron was a more certain cure than cod-liver oil, and was the first to record spontaneous cures.

In the present century, Pillat (1929a) assumed that the spots were due to vitamin A deficiency; he also noted that they nearly always disappeared when an improved diet including cod-liver oil was given, that they were found in the early stages of deficiency and that they were not always associated with night-blindness (Pillat, 1929b). Nicholls $\&$ Nimalasuriya (1939) deviated even further from Bitot's original description, saying that the spots were seldom accompanied by night-blindness. They observed that in Ceylon the moist foamy spot reported by Herbert (1897) in India and Tobgy (1935) in Egypt did not occur, but only the type described by Bitot as 'pearly'. They found the lesion very hard to cure with massive doses of vitamin A. Oomen (1958) also was doubtful as to the efficacy of vitamin $A$, stating that the spots might remain unaffected for weeks, or not be cured at all. Appelmans, Lebas \& Missotten (1956) concluded that vitamin A had no therapeutic effect on the spots, describing them as 'medically irreversible' and as 'the indelible signature of a transitory deficiency'. Thus, workers in the nineteenth century seem to have had much better results than contemporary workers in curing the condition.

In a recent paper, Rodger (1960), after discussing Pillat's arguments, said that he had seen several cases of Bitot's spots, of the pearly type, among children of rich and educated Africans and Indians, in which vitamin A deficiency was unlikely in view of the child's good health throughout life and lack of poverty. This was also the experience of Gupta (1956) in India. Rodger also pointed out that many cases of diffuse (seasonal) xerophthalmia regressed spontaneously, leaving various recognizable residua, but that Bitot's spots was not one of them. In an earlier work he remarked on the rarity of the spots among West Africans in whom xerophthalmia and keratomalacia were not uncommon (Rodger, 1958). McLaren (1960) confirmed this observation, reporting that in East Africa the incidence of the spots was no higher where xerophthalmia and keratomalacia were rife than where these lesions were not seen. His patients did not show low plasma vitamin A levels or impairment of dark adaptation. He believed that there was insufficient evidence to attribute Bitot's spots to a deficiency of vitamin A.

There is thus disagreement concerning nearly every feature of Bitot's spots since modern techniques have been introduced into tropical countries. Probably the most 
interesting observation we made under the microscope was that, whereas mucus cells were rare locally in both types of spot, in the mucoid they had multiplied considerably in the upper fornix. This is the probable source of the mucoid debris. Whether we are dealing with an infective catarrh of the conjunctiva supcrimposed on a Bitot's spot of the classical type or a reaction due to a primary or secondary deficiency is difficult to say, but the evidence points to the former. Abnormal viscous secretions will not attach themselves to healthy conjunctiva, as we have proved to our own satisfaction by inserting lamp black in the lower fornix. If this is done in an eye in which a spot is already present, after wiping the debris away, the lamp black will attach itself to the area of the spot and only to that area. The explanation is without doubt physical. If, then, a conjunctival catarrh develops where a pearly spot already exists, one would expect the abnormal secretion to be found attached to the spot, not lying free in the lower fornix.

Stephenson ( 1898$)$ isolated the xerosis bacillus from the pearly debris and cultured luxurious colonies on blood agar within $16-48 \mathrm{~h}$. He claimed the appearances of these colonies was identical with the pearly-grey debris of the fully formed spot. He emphasized that, although it was well known this organism was non-pathogenic, nobody had tested the belief by inoculating the conjunctiva of man (or of an animal) with the bacillus when debility, starvation and local damage to the epithelium had previously been superimposed on a vitamin A deficiency.

Taking all the available evidence into consideration it seems highly unlikely that a primary vitamin A deficiency gives rise to Bitot's spots. If, on the other hand, a slight traumatic xerosis were to develop, as a result, say, of excess u.v. or i.r. rays, or exposure to dust, or both, the Bitot area is the one most likely to be affected. In such circumstances any coincidental reduction in the vitamin A status, or a constitutional metabolic anomaly affecting, say, its utilization, would undoubtedly further affect the health of the epithelium; the resultant metaplasia would then provide a pabulum for bacteria and an adhesive core for mucus. Although it is easy to imagine such a thing happening in tropical countries, it is not so easy to picture it occurring in England during the nineteenth century when so many cases were reported: there may, of course, have been circumstances at that time, unknown to us, which would have caused irritation of the exposed conjunctiva. One cannot, we feel, ignore the probable role of thermal or other mild forms of trauma. Evetzki ( 1890 ) reported a high incidence of circumscribed epithelial xerosis of the conjunctiva among glass workers working at great heats, none of whom complained of night-blindness and none of whom, as far as he knew, suffered from any other disease. Until Bitot's spots are reproduced experimentally, such conjectures are probably as far as we shall ever get.

A recent paper by Aydelotte (1963) may help one day to explain the nature of Bitot's spot. This study demonstrates in embryonic chicks the effect on the epithelial differentiation of citral, which is widely consumed in citrus fruit peels and citronella leaves, used in curries. In high concentrations this substance was found to stimulate deviation of the basal cells so that the epithelium became stratified and sometimes keratinized; in addition the differentiation of mucus cells was inhibited. 


\section{SUMMARY}

I. Sixty-two northern Indians of both sexes and of varying ages, each exhibiting Bitot's spots, were examined.

2. By comparison with the results in 108 subjects with healthy eyes, the blood levels of those with Bitot's spots were--with four exceptions-within the normal range, and the mean values did not differ from normal. The light thresholds were raised in three subjects only.

3. Two kinds of spot were identified, the pearly and the mucoid. In the former Corynebacterium xerosis had proliferated abundantly among the debris, which it is thought accounted for the pearly appearance. In the latter there was marked proliferation of the mucus-secreting cells in the upper fornix in association with bulbar hyperaemia; it is believed that this is part of an inflammatory catarrh of the conjunctival epithelium and that the excessive mucus covers a pre-existing pearly spot to form the mucoid.

4. The anatomical changes underlying both types of debris were identical, ranging from epithelial hyperplasia to a stratified squamous metaplasia with loss of the mucussecreting cells in the area covered by the spot.

5. Massive vitamin $A$ therapy by mouth and intramuscularly had no effect on Bitot's spots, even after many months' administration.

6. We are unable to suggest how Bitot's spots originate. The effect of slight trauma, in particular thermal trauma, seems worth investigating, although the aetiology is probably more complex and as likely to be related to a metabolic disorder as to malnutrition. Recent work suggests that citral or a similar substance may be implicated in a disorder of metabolism concerned with the appearance of the spots.

We are greatly indebted for the encouragement and co-operation afforded us by the late Dr Mohan Lal, Chief Medical Officer of the Gandhi Eye Hospital, whose loss is so bitterly felt.

A Goldmann-Weekers Dark Adaptometer, a Bausch and Lomb colorimeter, and the vast quantity of vitamin A preparations (Arovit) required were given by HoffmanLa Roche Ltd, Basle. A Cambridge colorimeter and Pye galvanometer, a second dark adaptometer, and Aimark slit lamp were supplied by the United Kingdom as a contribution under the Colombo Plan. For these generous gifts we express sincere thanks.

\section{REFERENCES}

Appelmans, M., Lebas, P. \& Missotten, A. (1956). Bull. Soc. belge Ophtal. 113, 327.

Aydelotte, M. B. (1963). Y. Embryol. exp. Morph. r1, 279.

Berliner, M. L. (1949). Biomicroscopy of the Eye. Vol. I, p. I67. New York: Paul B. Hoeber Inc.

Bitot, C. (1863). Gaz, hebd. Méd. Chir. ro, 284.

Bloch, C. E. (1921 a). Fb. Kinderheilk. 89, 405.

Bloch, C. E. (1921 b). J. Hyg., Camb., r9, 283.

Burch, H. B., Salcedo, J., Carrasco, E. O. \& Intengan, C. L. (1952). J. Nutr. 46, 239.

Evetzki, A. (1890). Arch. Ophtal., Paris, July/August, p. 377.

Goldblatt, H. \& Benischek, M. (1927). F. exp. Med. 46, 699.

Gupta, S. P. (1956). Report of All-India Ophthalmological Conference, p. 9 r. New Delhi: Government Printer. 
British Fournal of Nutrition, Vol. ${ }_{17}, \mathrm{No} .4$

Plate I

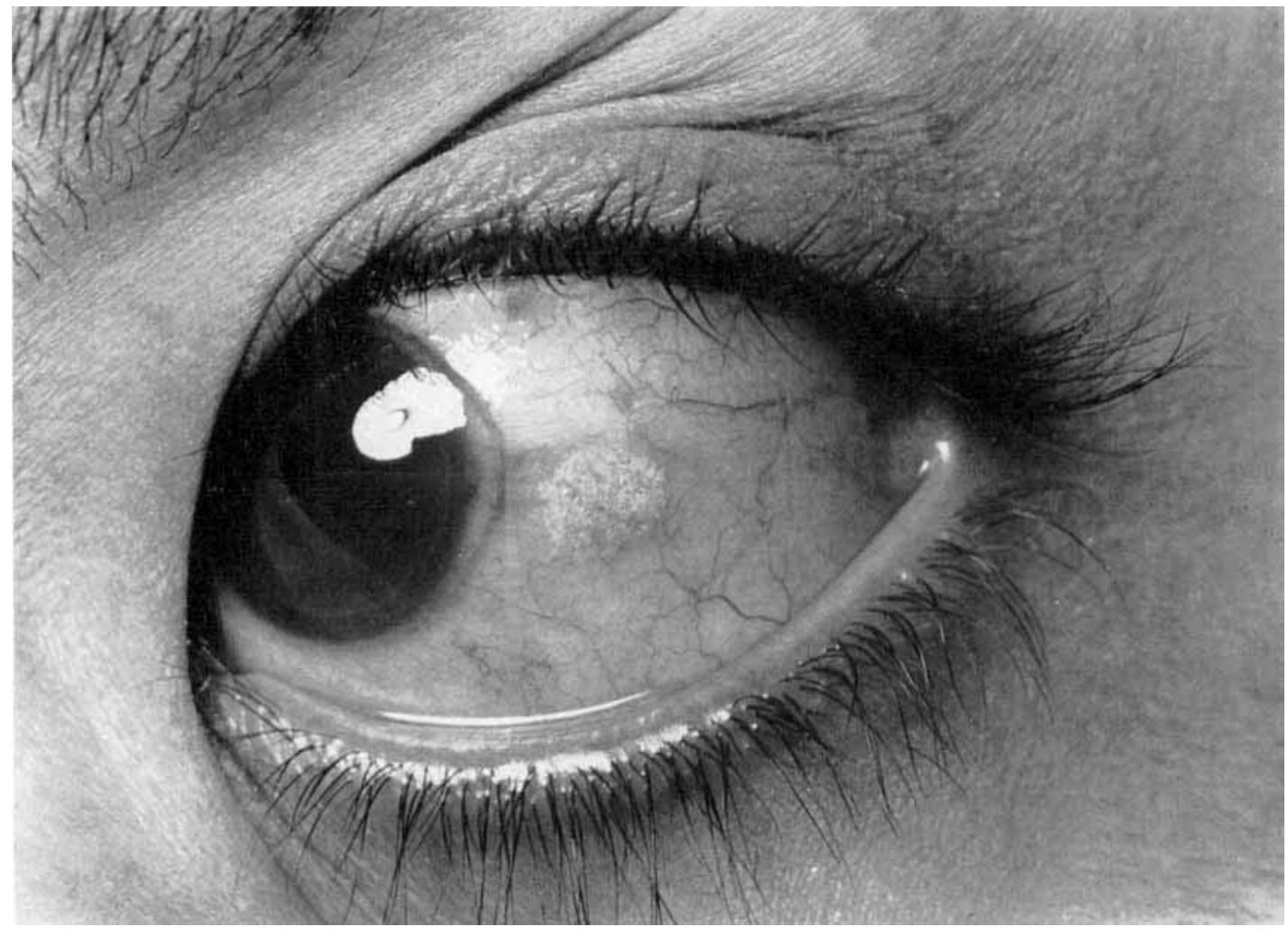

F. C. RODGER, H. SAIDUZZAFAR. A. D. GROVER AND A. FAZAL

(Facing p. 484) 
British Fournal of Nutrition, Vol. I7, No. 4

Plate 2

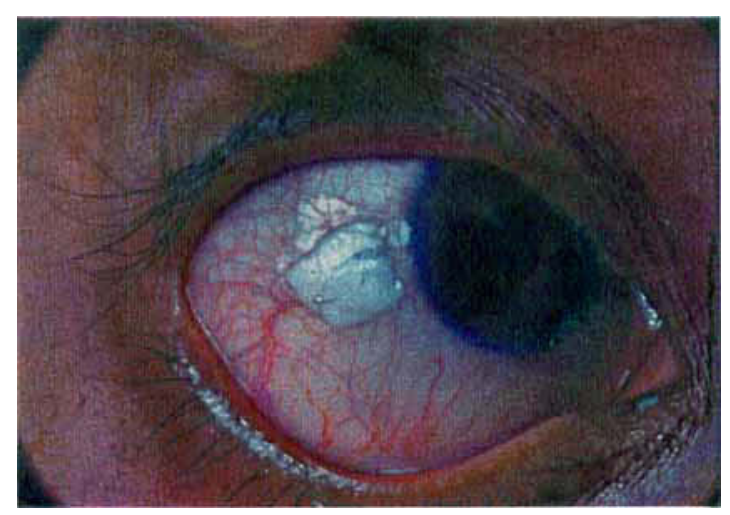

F. C. RODGER, H. SAIDUZZAFAR. A. D. GROVER ANI A. FAZAL 
Herbert, G. H. (1897). Indian med. Gaz. 32, 1 30.

Hubbenet, M. (1860). Ann. Oculist., Paris, 44, 293.

McCollum, E. V. \& Simmonds, N. (1917). F. biol. Chem. 32, 181,

McLaren, D. S. (1960). Proc. Nutr. Soc. 19, 89.

Moore, T. (1957). Vitamin A, p. 586. London: Elsevier.

Nicholls, L. \& Nimalasuriya, A. (1 939). Lancet, 236, 1432.

Oomen, H. A. P. C. (1958). Fed. Proc. 17, Suppl. no. 2, p. III.

Osborne, T. B. \& Mendel, L. B. (1921). F. Amer. med. Ass. 76, 905.

Pillat, A. (1929a). Nat. med. F. China, 15,614.

Pillat, A. (1929b). Nat. med. Y. China, I5, 588.

Rodger, F. C. (1958). Brit. F. Ophthal. 42, 336.

Rodger, F. C. (1960). Proc. Nutr. Soc. 19, 80.

Rodger, F. C., Dhir, P. K. \& Hosain, A. T. M. M. (1960). Arch. Ophthal., Chicago, 63, 927.

Saemisch, T. (1876). Handb. Augenheilk. 4, 128.

Snell, S. (1880-1). Trans. ophthal. Soc. U.K. 1, 207.

Stephenson, S. (1898). Trans, ophthal. Soc. U.K. 18, 55.

Tobgy, A. F. (1935). Bull. Soc. Ophtal. Égypte, 28, 79.

Treacher Collins, E. (1930). Trans, ophthal. Soc. U.K. 50, 201.

Yap-Kie-Tiong (1957). Brit. F. Nutr. I r, 158.

\section{EXPLANATION OF PLATES}

Pl. 1. Bitot's (pearly) spot. The white mark is the reflection of the flash bulb. P1. 2. Bitot's (mucoid) spot. 